\title{
Genotype by Environment Interaction and Yield Stability in Bread Wheat Cultivars under Rainfed Conditions
}

\author{
Fatma Ibrahim Mohamed Abd EL-Ghany ${ }^{1}$, Mohamed Abd El-Hammed Attia*1, Ashraf Nour \\ El-Sadek ${ }^{1}$, Ali Nawar², Abla Mohamed Dessouky ${ }^{1}$, Ahmed Mahgoub Shaalan ${ }^{3}$ \\ ${ }^{1}$ Desert research center, Al Materia, Cairo, Egypt, ${ }^{2}$ Department of crop science, Alexandria University, \\ Alexandria, Egypt, ${ }^{3}$ Faculty of Desert and Environmental Agriculture, Matrouh Branch, Alexandria University, \\ Egypt \\ *Corresponding author: dr. Mohamed Abd El-Hammed Attia E-mail: mattiadrc2017@gmail.com
}

Received on : 16-11-2020

Accepted on: 21-1-2021

\section{ABSTRACT}

The concept of stability is important for the selection of the crop cultivars and in the breeding programs. The aim of this work was to evaluate the productivity of some bread wheat cultivars under rainfed conditions of different locations in the NWCZ of Egypt. Results of the current study showed that the studied cultivars performed differently in the different environment. AMMI analy sis revealed that the environment was responsible for most of the cultivars yields variation also AMMI2 bi-plot revealed that East Barrani in the first seas on was the most favorable environment for all cultivars, and Sakha 94 was the superior cultivar in this environment. According to the Eberhart and Russel (1966), Sakha 94 was the most stable cultivar followed by Misr-1 Sakha-93 cultiv ar is considered as the most stable high yielding genotypes under both moderate and severe drought conditions.

KEYWORDS: Environment Interaction, Genotype, Rainfed Conditions, Wheat, Yield Stability.

\section{INTRODUCTION}

In Egypt, wheat is the most important staple crop in the country and an essential component of the Egyptian diet. According to the United States Department of Agriculture (Donley, 2020) total wheat production in Egypt is 9.5 million tons, and the total consumption is 20.4 million tonnes, compared 20.1 million tonnes the previous year. It attributes the uptick to an increase in food, seed and industrial (FSI) use consumption.

"The rise in FSI wheat consumption is attributable to population growth of about $2.4 \%$ per annum," the USDA said. "Egypt, with a population of 99.4 million, is adding over 2 million people per year. It also is host to an estimated 5 million refugees from Iraq, Syria, Libya, Yemen and Sudan." The wide gap between consumption and actual production forces the country to import 11 million tons to close this gap. Therefore, selecting the most adapted high yielding cultivars is one of the most important breeding programs in the country.

The cultivar performance, in an environment, is the production of the genotypic, environmental and the interaction between the genotypes and the environmental effects (Donley, 2020). These effects give the cultivars their phenotypic values, used to select the high yielding and more stable cultivars in the different environments. Genotype by environment interaction is defined as the variation of the environmental conditions, such as drought, temperature, disease pressure, stress etc. which results in different genes expression in the same genotype but not necessarily, of different rank orders of genotypes through the tested environments (Purchse, 1997), crop improvement programs include examining many genotypes in a wide range of environments, including stress and non-stress environments. Genotypes, producing higher and stable yields under stress conditions, e.g., water scarcity, can be recommended for such environments. Dencis, et al., (2000), Yan and Hunt 2001)

The concept of stability is important for the selection of the crop cultivars and in the breeding programs. In the multi-environment trials, the phenotypic performance of a genotype is not necessarily, the same under the diverse environments 
(Ali, et al., (2003). Some genotypes may produce a good yield under a certain environment and fail in several others. The stability could be a challenge, not only for changing the test environment but also, the growing season (Tarakanovas and Ruzgas 2006). High yield stability means that the genotype produces similar (high or low) yield under a wide range of environments (Tarakanovas and Ruzgas 2006) and all new improved cultivars should be adapted to a wide range of adverse environments.

There are several methods to estimate the genotype stability across different environments, some of these methods are univariate parametric methods, such as regression coefficient and deviation mean square (Eberhart and Russal, 1966), unbiased estimate of variance (Shukla, 1972) covariance of the sum of square (Wricke 1962; Lin et al., 1986; Becker and leon, 1988) joint regression (finlay and Wilkinson 1963; Westcott 1986; lin et al., 1986; Becker and Leon 1988), the slope of the regression line (lin et al., 1986; Becker and leon 1988) the coefficient of determination (Bilbro and Ray1976) and coefficient of variation or variance of genotype means (Jalaluddin and Harrison1993), With these univariate statistical methods, there are some of the multivariate methods to estimate stability such as the additive main effect and multiplicative interaction (AMMI model (Zobel et al., 1988) and bi-additive models (Denis and Gower 1994)

The additive main effects and multiplicative interaction MMI (Zobel et al., 1988) and the Eberhart and Russell regression (ERR, Eberhart and Russell
,1966) methods have been used, extensively, among all stability statistics. The ERR regresses is the line yield within an environment on an index of environment productivity, which is generally calculated as the average yield of the environment (Eberhart and Russell, 1966). The ERR method has been shown to be a subclass of AMMI that tests a specific hypothesis (Gauch1988). Both of these methods belong to the concept of dynamic stability (Mohamadi et al., 2012) also the two of extract a pattern from GEI and use it to estimate stability.

The main objectives of this study were 1) to evaluate the productivity of some bread wheat cultivars under rainfed conditions of different locations in the NWCZ of Egypt.

2) to determine the most suitable cultivar for each location by evaluating the genotype by environment interaction using, the AMMI biplot model.

\section{MATERIALS AND METHODS}

\subsection{Description of the study area}

In order to identify the GEI, field experiments were conducted during the three growing seasons $(2013 / 2014 ; 2014 / 2015$ and $2015 / 2016$ at nine different environments along the north western coast of Egypt. The environments were a combination of seasons and locations (Table 1). Six wheat cultivars were grown under the rainfed conditions at the studied locations. Locations coordinates, sowing dates and harvesting dates for the experimental sites are presented in Table (1).

Table 1. Geographic coordinates, sowing and harvesting dates of the locations under study.

\begin{tabular}{|c|c|c|c|c|c|}
\hline & Location & Latitude & Longitude & Sowing date & Harvesting date \\
\hline $\begin{array}{l}\text { First season } \\
2013 / 2014\end{array}$ & Eest Barrani & $31.60^{\circ}$ & $25.86^{\circ}$ & Dec. 2013 & May 2014 \\
\hline \multirow{3}{*}{$\begin{array}{l}\text { Second season } \\
2014 / 2015\end{array}$} & Ras Elhakma & $31.10^{\circ}$ & $27.62^{\circ}$ & 16 Dec. 2013 & 12May 2014 \\
\hline & Ras Elhakma & $31.10^{\circ}$ & $27.62^{\circ}$ & 26 Nov. 2014 & - \\
\hline & Marsa Matrouh & $31.34^{\circ}$ & $27.14^{\circ}$ & 4 Jan. 2015 & - \\
\hline \multirow{7}{*}{$\begin{array}{l}\text { Third season } \\
2015 / 2016\end{array}$} & El Neguila & $31.43^{\circ}$ & $26.50^{\circ}$ & 5 Jan. 2015 & - \\
\hline & West Barrani & $31.60^{\circ}$ & $25.86^{\circ}$ & 23 Dec. 2014 & 28April2015 \\
\hline & East Barrani & $31.57^{\circ}$ & $25.99^{\circ}$ & 11 Jan. 2015 & - \\
\hline & Ras Elhakma & $31.10^{\circ}$ & $27.62^{\circ}$ & 9 Nov. 2015 & 24 April 2016 \\
\hline & El Neguila & $31.43^{\circ}$ & $26.50^{\circ}$ & 1 Dec. 2015 & 12 April 2016 \\
\hline & East Barrani & $31.60^{\circ}$ & $25.86^{\circ}$ & 10 Nov.2015 & 12 April 2016 \\
\hline & West Barrani & $31.36^{\circ}$ & $25.52^{\circ}$ & 7 Nov. 2015 & 23 April 2016 \\
\hline
\end{tabular}




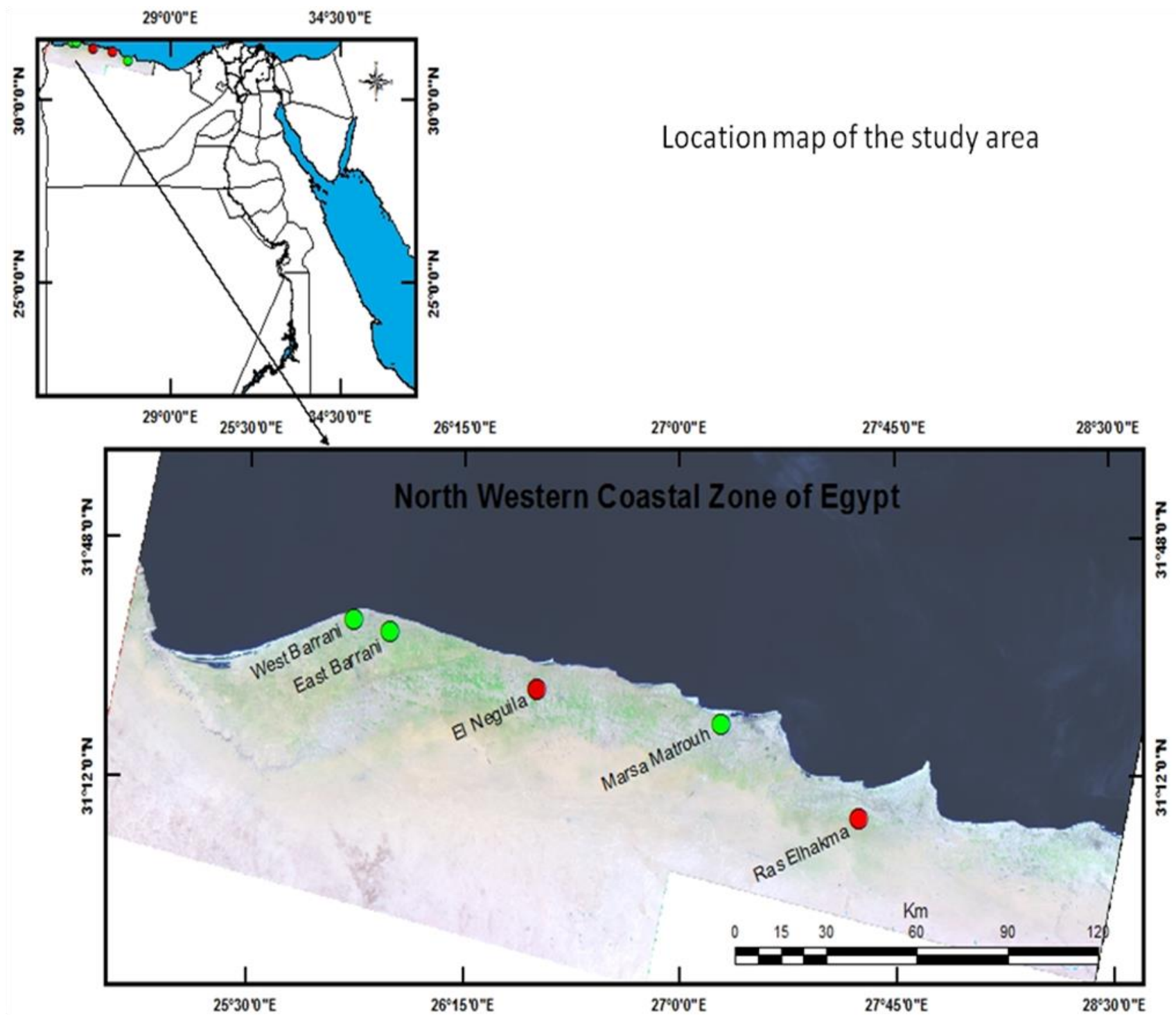

At each location, the experiment was laid out in a split plot design in randomize complete block design (RCBD) with three replications. The plot size was $10.5 \mathrm{~m}^{2}(3 \times 3.5 \mathrm{~m})$. Seeds were sown after the first effective rain during the rainy season. The rainfall average and distribution during the grown seasons at the different locations are presented in Table (2).

Table 2. Monthly total precipitation over the studied locations at the three growing seasons.

\begin{tabular}{llllllll}
\hline \multirow{2}{*}{ Month } & East Barrani & Ras elhekma & West Barrani & East Barrani & West Barrani & Ras Elhekma \\
& $2013 / 2014$ & $2013 / 2014$ & $2014 / 2015$ & $2015 / 2016$ & $2015 / 2016$ & $2015 / 2016$ \\
\hline Oct. & 1.260 & 1.10 & 0.00 & 15.42 & 13.26 & 2.790 \\
Nov. & 1.060 & 13.74 & 1.17 & 40.16 & 49.31 & 23.49 \\
Dec. & 25.11 & 53.03 & 9.48 & 84.78 & 139.76 & 94.11 \\
Jan. & 85.27 & 27.54 & 49.03 & 9.54 & 36.18 & 58.46 \\
Feb. & 18.83 & 19.02 & 7.80 & 9.19 & 0.00 & 18.89 \\
Mar. & 0.00 & 2.908 & 7.14 & 1.96 & 0.915 & 13.90 \\
Apr. & 2.974 & 1.362 & 0.00 & 0.90 & 0.00 & 7.79 \\
Total & 134.5 & 118.70 & 74.61 & 161.94 & 239.43 & 219.4 \\
\hline
\end{tabular}


Data from individual locations were subjected to statistical analysis using analysis of variance (ANOVA) to determine the significance of the main effects and their interaction. Least Significant Difference (LSD) was used to obtain the significant difference between individual means according to Gomez and Gomez (1984) using Crop Stat 7.2 statistical software package developed by IRRI (IRRI, 2009). Eberhart and Russell's joint regression analysis ( $\mathrm{S}^{2} \mathrm{di}$ ), (Eberhart and Russell, 1966) was used in the domain of crop Stat 7.2 statistical softw are package. The analysis was performed using the model as:

\section{$Y I J=\mathrm{M} I+\mathrm{B} I I J+\Delta I J$}

where YIJ is the adjusted mean phenotypic value for the $I \mathrm{TH}$ line at the $J \mathrm{TH}$ environment, $M I$ is the overall mean of $I \mathrm{TH}$ line, $B I$ is the regression coefficient from the ERR (estimated as B, the ERR stability index), IJ is the environmental index, and $\Delta I J$ is the residual error. This statistical method has two indices to measure the genotypes stability across different environments:

\section{1-Regression coefficient}

$b_{i}=1+\frac{\left(\sum_{i}\left(x_{i j}-\bar{x}_{i}-x_{. j}^{-}+\bar{x}_{m}\right)\left(x_{. j}^{-}-\bar{x}_{\mathrm{e}}\right)\right.}{\left(\sum_{i j}\left(x_{. j}^{-}-\bar{x}_{\mathrm{e}}\right)^{2}\right.}$

2- Variance of the regression deviations

$\mathrm{s}_{\mathrm{di}}^{2}=\frac{1}{E-2}\left[\sum_{\mathrm{i}}\left(x_{i j}-\bar{x}_{i}-\bar{x}_{. j}+\bar{x}_{n}\right)-\left(b_{i}-1\right)^{2} \sum_{i}\left(\bar{x}_{. j}-\bar{x}_{. .}\right)^{2}\right.$

where $X_{i j}$ is the value of genotype $i$ at the environment $\mathrm{j}, \bar{x} i$ is the mean of genotype $i, \bar{x} \cdot j$ is the mean of environment $j, \bar{x}_{m}$ is the grand mean, and $\mathrm{E}$ is the number of environments.

The Additive Main effect and Multiplication Interaction AMMI model suggested by Zobel et al.,1988 was used as follows:

$\mathrm{Y}_{i j}=\mu+\alpha_{i}+B_{j}+\sum_{\mathrm{n}=0}^{\mathrm{N}} \lambda_{n} \gamma_{i n} \delta_{j n}+\theta_{\mathrm{ij}}+\varepsilon_{\mathrm{ij}}$

where $\mu$ is the overall mean, $g i$ is the effect of $i$ th genotype, $e j$ is the effect of $j$ th environment, $\sum_{n-1}^{N} \lambda$ nүinōjn + pij is the GEI and $\lambda \mathrm{n}$ is the eigenvalue of $n$th interaction principal

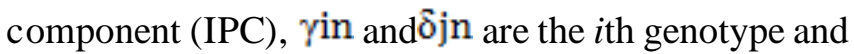
$j$ th environment eigenvectors for the $n$th IPC, and $\rho i j$ is the GEI residuals.

The degrees of freedom (DF) for the IPCA axis were calculated based on the following method (Zobel et al., 1988). DF = G + E - 1-2n;
Where: $\mathrm{G}=$ the number of genotypes, $\mathrm{E}=$ the number of environments and $n=$ the $n^{\text {th }}$ axis of IPCA.

The biplot display of principal component analysis was used to identify stress-tolerant and highyielding cultivars and to study the interrelationship between the stress-tolerant attributes. The principal component analysis and principal component plot were done using crop Stat 7.2 statistical software package.

\section{RESULTS}

\subsection{Eberhart and Russell model}

According to Eberhart and Russell statistical method (Eberhart and Russell 1966) for studying the stability of different genotypes grown in a number of environments, a genotype could be considered as stable when it has a coefficient of regression $(b i)=1$ and deviation from regression $=0$. Based on the data presented in Table 3, the coefficient of regression for the studied cultivars ranged from. 0.293 to 1.498 . Based on grain yield, Sakha 94 has a bi value of 1.107 followed by Misr 1(0.879) which are considered the most stable cultivars (closer to 1) as compared to the other cultivars, while Gemmiza 11 has a bi value of 0.293 followed be Giza 1681.498 and these cultivars are considered as unstable cultivars.

According to the deviation from regression values which ranged from 0.00 to 0.08 , Gemmiza 11 has the lowest value of deviation from regression 0 followed by Giza $168(0.01)$ and Sides $12(0.01)$ which considered as the most stable cultivars while Sakha 93 has the highest values of deviation from regression (0.08) followed by Sakha $94(0.05)$ which can be classified as less stable cultivars as compared to the others. The coefficient of determination varied from $2 \%$ recorded by Sakha 94 to $96 \%$ which produced by Gemmiza 11 .

It can be concluded that Sakha 94 produced the closest to 1 value for the bi (1.107) and Gemmiza 11 produced the low est deviation from regression of 0 . Different ranking of genotypes according to their stability based on these two coefficients are stated by Gebru, and Abay, 2013, Rasul et al., 2006 and Sayar et al., 2013. However, some studies found the regression coefficient to be better indicator for genotypic response under varying environments based on Finly and Wilkinson (1963), where stability is expressed as a linear relationship between the yield of genotypes over many environments i.e., the regression coefficient (bi), and a genotype with $b i=1$ can be considered stable. 
Scientific Journal of Agricultural Sciences 3 (1): 56-65, 2021

Table 3. Stability parameters of wheat cultivars for the grain yield.

\begin{tabular}{cccccccc}
\hline Cultivar & Mean yield (t/ha) & $\mathrm{b} i$ & $\mathrm{SE}$ & MS-TXL & MS-REG & $\mathrm{S}^{2} \mathrm{~d} i$ & $\mathrm{R}^{2}(\%)$ \\
\hline Sakha 93 & 0.60 & 1.40 & 0.459 & 0.07 & 0.06 & 0.08 & 16.00 \\
Sakha 94 & 0.55 & 1.107 & 0.428 & 0.04 & 0.00 & 0.05 & 2.00 \\
Misr1 & 0.44 & 0.879 & 0.272 & 0.02 & 0.01 & 0.03 & 5.00 \\
Giza168 & 0.66 & 1.498 & 0.236 & 0.03 & 0.06 & 0.01 & 69.00 \\
Gemmiza 11 & 0.42 & $0.293^{*}$ & 0.106 & 0.04 & 0.12 & 0.00 & 96.00 \\
Sids 12 & 0.34 & 0.703 & 0.144 & 0.01 & 0.02 & 0.01 & 59.00 \\
\hline
\end{tabular}

Whereas; $b i$ is the regression coefficient, MS-TXL is contribution of each cultivar to interaction MS .MS-REG is the contribution of each cultivar to the regression component of the cultivar by location interaction, $\mathrm{S}^{2} \mathrm{~d} i$ is the regression deviation mean square, $\mathrm{R}^{2}$ is the coefficient of determination.

This method was modified from regression analysis which originally proposed by Yates and Cochran (1938).

The main problem with stability statistics is that they don't provide an accurate picture of the complete response pattern (Holhas, 1995). The reason is that a genotype's response to varying environments is multivariate (Lin et al., 1986) whereas the stability indices are usually univariate.

Through multivariate analysis, genotypes with similar responses can be clustered, and thus the data can be summarized and analyzed more easily (Gauch, 1982; Crossa, 1990). Characterization of the response patterns of genotypes to environmental change enables extrapolation to a much wider range of environments than those tested (Holhas, 1995). One of the multivariate techniques is the AMMI model, AMMI model, (additive main effects and multiplicative interaction method). It combines the analysis of variance of genotypes and the environment main effects with principal component analysis of the GEI into a unified approach (Gauch, 1988; Zobel et al., 1988; Gauch and Zobel, 1990).

\subsection{AMMI analysis}

In this study 6 environments were cultivated by 4 wheat cultivars in the first and the second seasons, while in the third season two more cultivars were added. Grain yield for the missing cultivars in the first and second seasons were estimated by the software i.e., Cropstat and the genotype by Environment interaction were tested using the AMMI model.

The AMMI analysis for the grain yield $(\mathrm{Kg} / \mathrm{ha})$ of the tested genotypes and locations showed that $(59.38 \%)$ of the total sum squares was due to the environmental effects while the genotypes showed $11.7 \%$ of the total sum of squares and the genotype by environment interaction attributed with $29.34 \%$ of the sum of squares (Table 4). A large percent of the sum squares for the environment indicated that environments were diverse which cause the most of the variation in grain yield. In the analysis of variance, the sum squares of GxE were 2.5 times higher than that of genotypes.

Table 4. The analysis of variance of the AMMI model.

\begin{tabular}{ccccc}
\hline S.O.V. & df & S.S & M.S & Variation \% \\
\hline Cultivars & 5 & 350759 & 70151.8 & 11.70 \\
Environments & 5 & 1767680 & 353537 & 59.38 \\
Cultivars X Environments & 19 & 873451 & 45971.1 & 29.34 \\
AMMI COMPONENT 1 & 9 & 665686 & 73965.2 & 76.21 \\
AMMI COMPONENT 2 & 7 & 147500 & 21071.4 & 16.88 \\
AMMI COMPONENT 3 & 5 & 40593.3 & 8118.66 & 4.64 \\
AMMI COMPONENT 4 & 3 & 19623.6 & 6541.22 & 2.24 \\
\hline Total & 29 & 2976780 & &
\end{tabular}


The principal components (IPCs) were represented as IPC1, IPC2, IPC3 and IPC4. Two IPCs out of four were highly significant according to the AMMI analysis of variance, were IPC1 captured (76.21\%) of the genotype by environment interaction, while IPC2 represented $16.88 \%$ of the GXE interaction. The first two principal components collectively contributed to $93.09 \%$ of the total GEI.

Grain yield is a complex character which is an outcome of interactions between many plants traits, which are in turn influenced by their genetic makeup and the growing environments. Our results showed a change in the rankings of the cultivar under varying environments in regard to their grain yield, and the analysis of variance showed a significant difference between cultivars, environments and their interaction. The large sum square and highly significant mean square of environment indicated that the environments were diverse, the large differences among environmental means cased most of the variation in the grain yield. These findings are in agreement with those obtained by Mohammadi, et al., 2007, Farshadfar 2008, Nachit et al., 1992, BrancourtHulmel and. Lecomte .2016, Mohammadi and Amri 2013.

\subsection{AMMI 1 model}

Genotypes and environments that had IPCA1 values close to zero were characterized with a low interaction effect (Figure 2), being considered stable (wide adaptation) (De Vita et al 2010). Environments responded differently in regard to grain Yield. Ras Elhekma in 2015/2016 season had a high negative IPCA1 value, with environmental mean being > the grand mean. Also, East Barrani in 2013/2014 had a high positive IPCA1 value, with environmental mean $<$ the grand mean. West Barrani in 2014/2015 and West Baranni in 2015/2016 had also at high positive IPCA1 value with environmental mean being close to the grand mean. On the other hand, Ras Elhekama in 2013/2014 had IPCA1 score of just under zero and an environmental mean close to zero, also east Barrani in 2015/2016 had IPCA1 value of just above zero and an environmental mean close to zero which indicate that they had a low interaction effect. From the above mention results two out of six locations i.e., Ras Elhekma in 2015/2016 season and East Barrani in 2013/2014 had high IPCA1 scores, indicating high $\mathrm{G} \times \mathrm{E}$ interactions.

Cultivars can be characterized also based on their interactions with the environments. Sids 12 cultivar had IPCA1 score close to the zero line, which indicate that it had a stable performance across the testing environments (Carbonell et al. 2008). On the other hand, Sakha 93 show large deviations from zero on the ordinate indicating specific adaptation to the environments with the same IPCA1 sign.

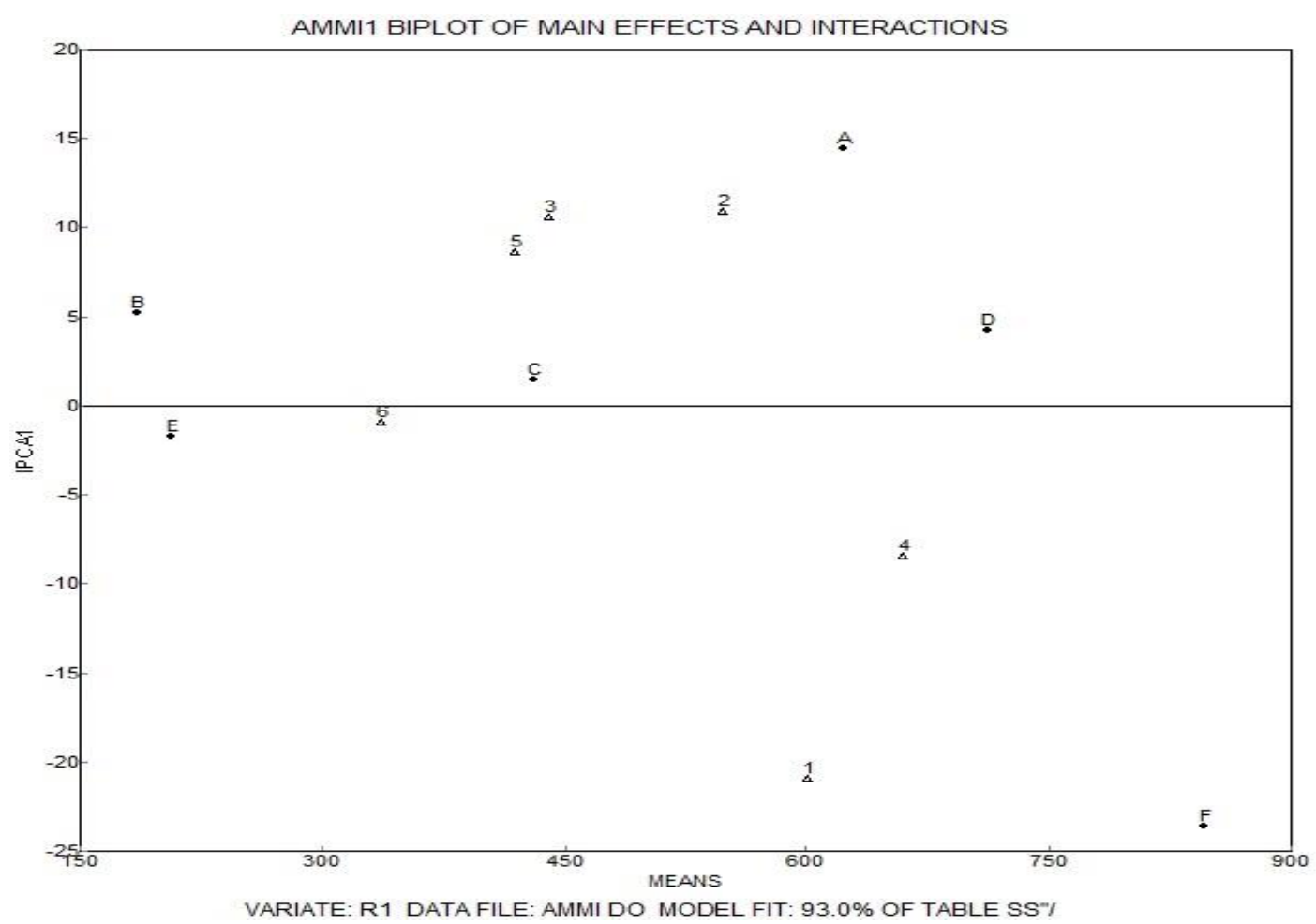

Fig 2. AMMI 1 Biplot of the main effects and interaction. 
Scientific Journal of Agricultural Sciences 3 (1): 56-65, 2021

\subsection{The AMMI2 model}

The vector length in the AMMI model can be used to determine the discriminative Yield. Ras Elhekma in 2015/2016 season had a high negative IPCA1 value, with environmental mean being > the grand mean. Also, East Barrani in 2013/2014 had a high positive IPCA1 value, with environmental mean $<$ the grand mean. West Barrani in 2014/2015 and West Baranni in 2015/2016 had also a high positive IPCA1 value with environmental mean being close to the grand mean. On the other hand, Ras Elhekama in 2013/2014 had IPCA1 score of just under zero and an environmental mean close to zero, also east Barrani in 2015/2016 had IPCA1 value of just above zero and an environmental mean close to zero which indicate that they had a low interaction effect. From the above mention results two out of six locations i.e., Ras Elhekma in 2015/2016 season and East Barrani vectors of RE 13, EB15 and WB 14 and another acute angle between WB15 and EB13 environments indicated that each two of these environments were similar for yield determination. Yet, environments with obtuse angle RE 15 and WB15, EB13 andWB14, WB14and RE15, RE13 and RE15 were different for yield determination. Sakha 94, GM and SD were the superior cultivar in Barrani 2013/2014, Barrani 2014/2015 and East Barrani 2015/2016 respectively.

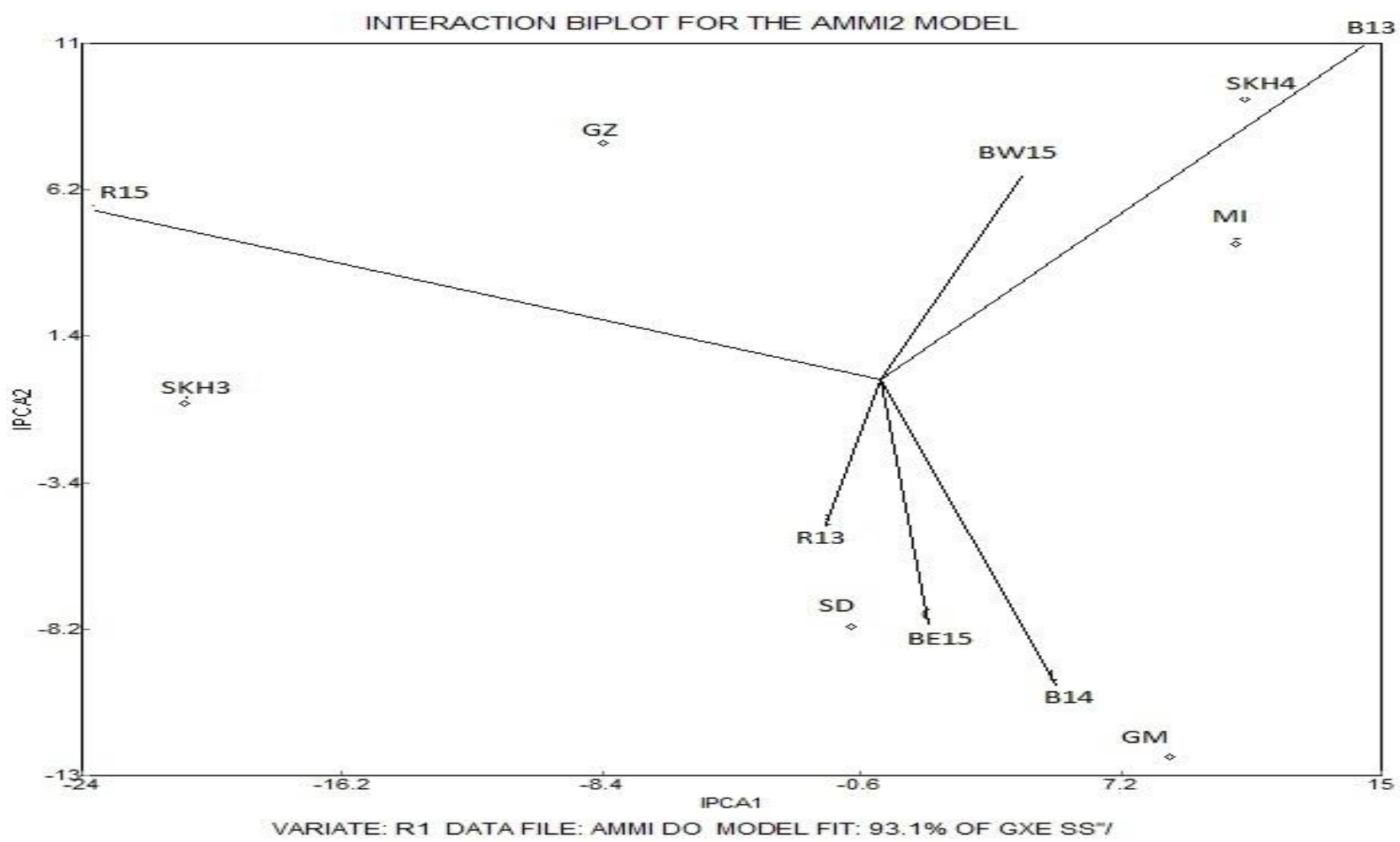

Fig 3. Interaction biplot for the AMMI2 model

The analysis of AMMI and principal component showed that there were a huge different among the studied environments which led to different yield performance among the tested cultivars. The mean square of the IPC1 and IPC2 were collectedly accounted for $93.09 \%$ of the GxE interaction. Thus, the AMMI with only the two interaction principal component axes was found to be the best predictive model. Similar results that found the first two principal components to predict validation observation (Huang et al., 2016., Kaya 2002).
In the AMMI-2 biplot the interaction between genotypes and environments can be clearly seen. The greater the IPC scores (positive or negative), the more adaptive genotype to certain environments. However, a genotype with IPCA scores close to zero show the high stability of such genotype to the all environments. our results show that Barrani 2013/2014 was the most favorable environment for all cultivars and Sakha 94 was the superior cultivar in this environment. 
For analyzing the $\mathrm{G} \times \mathrm{E}$ interaction, it was unavailable to grow all the cultivars in all the environments, thus producing unbalanced data which is common in plant breeding programs (Kang and Magari 1996). The unblancedness of the data can be classified as planned and unplanned (Searle 1987), and it has been studied by many researchers using different approaches (Gauch and Zobel, 1990; Rameau and Denis, 1992). In our case, we used the approach of Restricted Maximum Likelihood (REML) which is already CROPSTAT software built in and the missing mean yield of cultivars is calculated using the Best Linear Unbiased Predictors (BLUPs; Hendrson, 1975).

\section{CONCLUSION}

Results showed that the studied cultivars performed differently in the different environment and. AMMI analysis revealed that the environment was responsible for most of the cultivars yields variation also AMMI2 bi-plot revealed that East Barrani in the first season was the most favorable environment for all cultivars, and Sakha 94 was the superior cultivar in this environment. According to the Eberhart and Russel Sakha 94 was the most stable cultivar followed by Misr-1 Sakha-93 cultivar is considered as the most stable high yielding genotypes under both moderate and severe drought conditions.

\section{REFERENCES}

Ali N, Javidfar F, Mirza Y (2003). Selection of stable rapeseed (Brassica napus L.) genotypes through regression analysis. Pakistan Journal of Botany. 35: 175-183.

Becker H, Leon CJ (1988). Stability analysis in plant breeding. Plant Breeding. 101: 1-23.

Bilbro JD, Ray LL (1976). Environmental stability and adaptation of several cotton cultivars. Crop sciences .16:821-824.

Brancourt-Hummel M, Lecomte C (2003). Effect of environmental varieties on genotype $\times$ environment interaction of winter wheat: a comparison of biadditive factorial regression to AMMI Crop Sci., 43: 08-617.

Chiorato AF, Sérgio Carbonell AM, Dias LA, de Resende MDA (2008). Prediction of genotypic values and estimation of genetic parameters in common bean." Brazilian Archives of Biology and Technology. 51(3): 465-472.

Crossa J (1990). Statistical Analyses of Multilocation Trials. Advances in Agronomy. 44:5-85.

De Vita P, Mastrangelo AM, Matteu L, Mazzucotelli E, Virzi N, Palumbo M, Lo Storto M, Rizza F, Cattivelli L (2010). Genetic improvement effects on yield stability in durum wheat genotypes grown in Italy." Field Crops Research 119, no. 1 (2010): 68-77.

Dencics R kastori, Kobiljshi B, Duggan B (2000). Evaluation of grain yield and its component in wheat landraces under near optimal and drought conditions, Euphytica .113:43-52

Densis JB, Gower JC (1994). Asymptiontic covariance for the parameters of bi- additive model. Utilitias Math .46:193-205.

Donley A (2020). Egypt corn, wheat consumption rising. world grain. Com.

Eberhart SA, Russell WA (1966). Stability parameters for comparing varieties. Crop Science. 6: 36-40.

Fang S, Li J, Tian Y, Huang T, Chen X (2016). Learning discriminative subspaces on random contrasts for image saliency analysis. IEEE transactions on neural netw orks and learning systems, 28(5): 1095-1108.

Farshadfar E (2008). Incorporation of AMMI stability value and grain yield in singl non-parametric index (GSI) in bread wheat. Pakistan journal of biological science. 11(14):1791-1796.

Finlay KW, Wilkinson GN (1963). The analysis of adap $\neg$ tation in a plant breeding programme. Crop Pasture Sciences .14: 742-754.

Gauch HG (1988). Model selection and validation for yield trials with interaction. Biometrics 44:705-715.

Gauch HG, Zobel RW (1990). Imputing missing yield trial data. Theoretical and Applied Genetics 70:753-761.

Gomez KA, Gomez AA (1984). Statistical procedures for agricultural research. John Wiley \& Sons; 17:13.

Henderson CR (1985). Best linear unbiased prediction of nonadditive genetic merits in noninbred populations. Journal of animal science, 60(1):111-117. Holhas T (1995). Analysis of genotype environment interactions .South Africa journal of Science .91:121124.

IRRI (2009). Crop Stat 7.2 for Windows. Crop Research Informatics Laboratory, International Rice Research Institute, Los Banos, Philippines.

Jalaluddin MD, Harrison SA (1993) . Repeatability of stability estimators of grain yield in wheat. Crop Sciences .33:720-725.

Kang MS, Magari R (1996). New Developments in Selecting for Phenotypic Stability in Crop Breeding". In: Kang, M.S., Gauch, H.G. (eds.), Genotype-byEnvironment Interaction, CRC Press, Boca Raton, FL, 1-14. 
Kaya Y, Palta C, Taner S (2002). Additive main effects and multiplicative interactions analysis of yield performance in bread wheat genotypes across environments. Turkish Journal of Agriculture and Forestry. 26: 275-279.

Lan J (1998). Comparison of evaluating methods for agronomic drought resistance in crops. Acta Agric Boreali-occidentalis Sinica. 7: 85-87.

Li Z, Yu S, Lafitte HR, Huang N, Courtois B, Hittalmani S (2003). QTLx environment interactions in rice. I. Heading date and plant height." Theoretical and Applied Genetics 108(1): 141-153.

Lin CS, Binns MR, Lefkovitch LP (1986). Stability analysis: where do we stand. Crop Sciences. 26:894900.

Mohammadi M, Karimizade R, Sabaghnia N, Shefazadeh MK (2012). Genotype $x$ environment interaction and yield stability analysis of new improved bread wheat genotypes. Turkish Journal of Field Crops. 17(1): 67-73.

Mohammadi R, Amri A (2013). Genotypex environment interaction and genetic improvement for yield and yield stability of rainfed durum wheat in Iran. Euphytica, 192(2): 227-249.

Mohammadi R, Armion M, Shabani A, Daryaei A (2007). Identification of stability and adaptability in advanced durum genotypes using AMMI analysis. Asian Journal of plant science. 6(8):1261-1268.

Nachit MM, Nachit G, Ketata H, Gauch HG, Zobel RW (1992). Use of AMMI and linear regression models to analyze genotype-environment interaction in durum wheat. Theoretical and Applied Genetics, 83(5):597-601.

Purchase JL (1997). Parametric analysis to described $\mathrm{G} \times \mathrm{E}$ interaction and yield stability in winter yield.Ph.D Thesis. Department of Agronomy, Falculty of Agriculture, University of Orange Free State, Bloemfontein, South Africa. 4-83

Rameau C, Denis JB (1992). Characterization of environments in long-term multi-site trials in asparagus, through yield of standard varieties and use of environmental covariates. Plant Breeding. 109:183191.

Rasul I, Zulkiffal M, Anwar J, Khan SB, Hussain M, Riaz UD (2006). Grain yield stability of wheat genotypes under different environments in Punjab. J. of Agric. and Soc. Sci., 4:222-224

Sayar MS, Anlar al AE, Başbag M (2013). Genotype-Environment Interactions and Stability Analysis for Dry-Matter Yield and Seed Yield in Hungarian Vetch (Vicia pannonica CRANTZ.). Turk. J. F. Crops., 18(2): 238-246.
Searle SR (1987). Linear models for unbalanced data John Wiley \& Sons. New York. New York segregating populations in durum wheat. African Journal of Agricultural Research. 1:162-172.

Shukla GK (1972). Some statistical aspects of partitioning genotype-environmental component of variability. Heredity. 29: 237 - 245.

Tarakanovas P, Ruzgas V (2006). Additive main effect and multiplicative interactions analysis of grain yield of wheat varieties in Linthuania . Agronomy Research. 4(1) :91-98.

Westcott B (1986). Some methods of analyzing genotype-environment interaction .Heredity .56:243253.

Wricke G (1962). Method of understanding the biological diversity in field research. Pfianzenzuchtg.7: 92-146.

Yan W, Hunt LA (2001). Interpretation of genotype $x$ environment interaction for winter wheat yield in Ontario.Crop Sciences. 41 :19-25.

Yates F, Cochran WG (1938). The analysis of groups of experiments. Journal of agricultural sciences. 28:556-580.

Zobel RW, Wright MJ, Gauch HG (1988). Statistical analysis of yield trial. Agronomy Journal .80:388-393. 
Fatma I M. et al., 2021

الملخص العربي

\section{التركيب الوراثي عن طريق التفاعل البيئي والثبات المحصول في أصناف قمح الخبز تحت ظروف الزراعة المطرية}

فاطمة ابراهيم محمد عبد الغني'، محمد عبد الحميد عطية'، أثرف نور الصادق'، على عيسى ناجى نوار'، عبله محمد دسوقى' ،

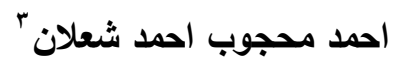

'مركز بحوث الصحراء، المطرية، القاهرة، مصر، ‘ُّم المحاصيل، كلية الزراعة، جامعة الاسكندرية، ׳كلية الزراعة الصحراوية والبيئية، جامعة

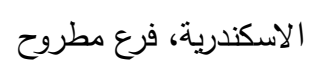

يعد مفهوم الاستقرار مهمًا لاختيار أصناف المحاصيل وفي برامج التربية. كان الهدف من هذا العمل هو تقييم إنتاجية بعض أصناف قدح الخبز

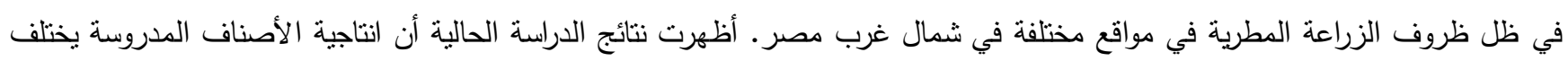

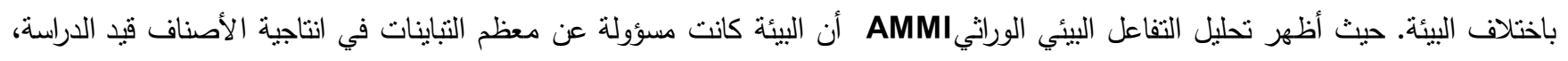

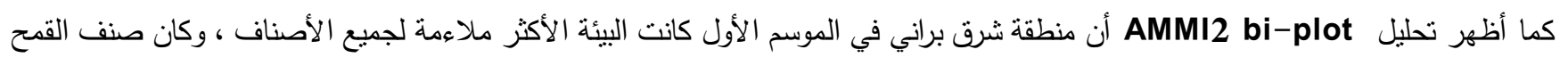

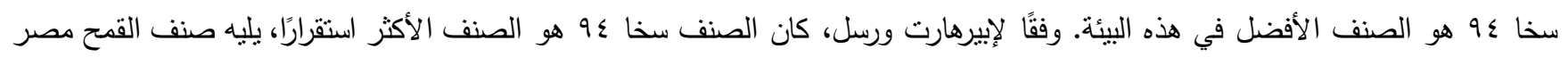

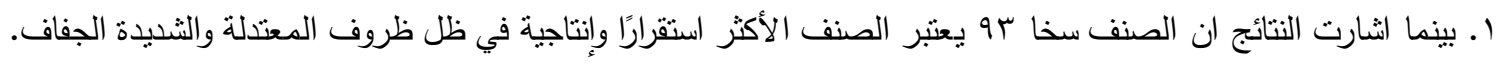

الكلمات المفتاحية: التفاعل البيئي -التركيب الوراثى - الظروف المطرية - القمح - الثنات المحصولى 